\title{
PESQUISAS COM CÉLULAS -TRONCO EMBRIONÁRIAS E A CONVENÇÃO AMERICANA DE DIREITOS HUMANOS - PACTO DE SAN JOSÉ DA COSTA RICA
}

\author{
Lílian Lúcia Graciano* \\ Flávia Cristina Piovesan ${ }^{* *}$
}

\begin{abstract}
RESUMO
Com o presente texto, buscar-se-á apresentar as questões advindas a partir dos avanços da biotecnologia, a partir da Lei $n^{\circ}$ 11.105/2005 - Lei de Biossegurança, mas especificamente à respeito das pesquisas com células-tronco embrionárias, e seus reflexos nos direitos humanos, principalmente em relação ao direito à vida. Sendo que para isso far-se-á uma análise do direito à vida no sistema regional americano, analisando seu principal instrumento, a Convenção Americana de Direitos Humanos Pacto de San José da Costa Rica.
\end{abstract}

Palavras-chave: direito à vida; células-tronco embrionárias; ser humano; Lei de Biossegurança; direitos humanos.

SUMÁRIO: INTRODUÇÃO - 1 ASPECTOS GERAIS E ATUAIS DOS AVANÇOS BIOTECNOLÓGICOS - 2 A ORIGEM DO EMBRIÃO - 3 CONSIDERAÇÕES SOBRE A PESSOA HUMANA - 4 O DIREITO À VIDA NA CONVENÇÃO AMERICANA DE DIREITOS HUMANOS (PACTO DE SAN JOSÉ DA COSTA RICA) - 5 CONSIDERAÇÕES FINAIS - REFERÊNCIAS.

* A autora foi pesquisadora do PIBIC/PUC-PR nos anos de 2000-2003, especialista em Direito Civil e Empresarial pela PUCPR, mestranda pela mesma instituição, bolsista CAPES, advogada e professora de direito. E-mail: liliangraciano@yahoo.com.br

** Co-autora orientadora do presente trabalho, professora doutora da Faculdade de Direio da PUCSP, professora da pós-graduação da PUCPR e PUCSP, professora do Programa de Doutorado em Direitos Humanos e Desenvolvimento da Universidade Pablo de Olavide (Sevilha, Espanha), procuradora do Estado de São Paulo. E-mail: flaviapiovesan@terra.com.br 


\section{INTRODUÇÃO}

O desenvolvimento das ciências e das técnicas, nos dois últimos séculos, trouxe consigo desafios, que têm relação com o surgimento de novos tipos de relações sociais no quadro cultural da tecno-civilização.

As ciências têm experimentado uma evolução nunca antes cogitada: a capacidade de criar e modificar os fundamentos da vida que, conseqüentemente, trazem novos problemas ao ser humano, na era contemporânea, e impactam diretamente na sociedade, e por se constituírem em temas que se convertem em fortes desafios mundiais, criam expectativas em grande parte da população.

Renasce o debate ético em todos os domínios da atividade humana, o paradigma científico domina cada vez mais as forças da natureza e, ao mesmo tempo, interfere de forma crescente no mundo natural, suscitando problemas que não encontram respostas no quadro da própria cultura tecnocientífica, em que surgiram e desenvolveram-se.

Nas palavras de Eduardo de Oliveira Leite:

As práticas biomédicas, tornadas mais audaciosas, graças a um desenvolvimento tecnológico inusitado, envolvem, a partir de agora, a vida humana de forma integral, apreendendo-a, dominando-a e corrigindo-a, de acordo com os interesses em questão, isto é, procurando melhorar sua qualidade e fazendo suas fronteiras recuarem, como se fôssemos aprendizes de Deus. ${ }^{1}$

A perplexidade humana à face das impressionantes mutações das possibilidades de interferência dos homens nos assuntos até então exclusivos da natureza ou da divindade, promove inquietantes indagações, algumas das quais nem sempre respondidas, ou não são respondidas satisfatoriamente, e nesta nova

${ }^{1}$ LEITE, Eduardo de Oliveira. Da bioética ao biodireito: reflexões sobre a necessidade e emergência de uma legislação. In: SIMPÓSIO DE BIOÉTICA E BIODIREITO, Londrina, 1999. 


\section{PESQUISAS COM CÉLULAS-TRONCO EMBRIONÁRIAS E A CONVENÇÃO AMERICANA DE DIREITOS HUMANOS - PACTO DE SAN JOSÉ DA COSTA RICA}

perspectiva surge o biodireito.

Cláudia Lima Marques, assevera sobre essa nova realidade, no sentido de que se vive na era da velocidade, o desenfreado avanço da tecnologia, das biotecnologias, onde o efêmero e o volátil parecem derrotar o permanente e o essencial. Vive-se a angústia do que não pode ser e a perplexidade de um tempo sem verdades seguras. Uma época aparentemente pós-tudo: pós-marxista, pós-kelsiana, pós-freudiana, o fim de uma era e de início de algo novo, ainda não identificado. ${ }^{2}$

A revolução terapêutica, mas principalmente as manipulações sobre a vida e o surgimento de novas formas de procriação, a utilização do ser humano e de seus elementos levou à produção de novas normas jurídicas.

Diante deste quadro o presente trabalho vem tratar da Lei de $n^{\circ} 11.105$, de 24 de março de 2005 (Lei de Biossegurança), especificamente de seu artigo $5^{\circ}$, que trata a respeito das pesquisas com células-tronco ${ }^{3}$ embrionárias, analisando o permissivo legal - sob a ótica do Pacto de San José da Costa Rica.

Conquanto, a Lei $\mathrm{n}^{\mathrm{o}} 11.105 / 2005$, destinada a regulamentar o artigo $225, \S 1^{\circ}$, incisos II, IV e V da Constituição da República de 1988, agrupa quatro relevantes matérias diversas: a pesquisa e a fiscalização dos organismos geneticamente modificados (OGM); a utilização de células-tronco embrionárias para fins de pesquisa e terapia; o papel, a estrutura, as competências e o poder da CTNBio; e, por fim, a formação do Conselho Nacional de Biossegurança - CNBS e sua organização, por meio de normas ora dispersas pelo texto integral da Lei, ora concentradas no capítulo II.

A Lei n ${ }^{o}$ 11.105/2005 regulamenta a utilização de células-tronco embrionárias para fins de pesquisa e terapia. Entretanto, esse tema sequer está mencionado no artigo $1^{\text {o }}$ que define os objetivos da Lei, e ainda, a contrário senso do que previa a legislação

${ }^{2}$ MARQUES, Cláudia Lima. A crise científica do direito na pós-modernidade e seus reflexos na pesquisa. Cidadania e Justiça, n. 6, p. 56, 1999.

${ }^{3}$ Células-tronco é o aportuguesamento da expressão inglesa stem cells, sendo também denominadas células estaminais ou células progenitoras. (LEITE, Eduardo de Oliveira. Grandes temas da atualidade - bioética e biodireito. Rio de Janeiro: Forense, 2004, p. 315). 
anterior (Lei 8.974/1995), abruptamente alterou a visão legislativa sobre o assunto.

Assim, abordar-se-á o direito à vida previsto no artigo $4^{\circ}$ da Convenção Americana de Direitos Humanos, tendo como objetivo central verificar se no referido sistema regional de proteção aos direitos humanos, existe, ou não, guarida às pesquisas com células-tronco embrionárias.

Para tanto, torna-se indubitavelmente necessário primeiro fazer uma abordagem dos aspectos gerais que torneiam as pesquisas com células-tronco embrionárias, apresentando um intróito sobre o assunto, a fim de contextualizar a temática, para então poder analisar o sistema regional Interamericano de proteção aos direitos humanos.

\section{ASPECTOS GERAIS E ATUAIS DOS AVANÇOS BIOTECNOLÓGICOS}

A história demonstra que o ser humano sempre conviveu com o fato biomédico, entretanto, atualmente, diante do crescente progresso e avanço científico e tecnológico surgem situações antes não vivenciadas. ${ }^{4}$

A cada dia a ciência passa a tornar um pouco mais apta a modificar todo o tipo de vida, inclusive a humana, e isso traz implicações profundamente perturbadoras à mente dos membros da sociedade. ${ }^{5}$

E nas palavras de June Goodfield, ao referir-se sobre transplantes de embriões:

E de novo, uma vez alcançados os conhecimentos básicos, está aberto o caminho não só para aplicação em proveito da humanidade, mas também para uma assustadora e condenável exploração em grande escala e às vezes, para nossa intranqüilidade, as duas coisas parecem

${ }^{4}$ GRACIANO, Lílian Lúcia. Reprodução humana medicamente assistida e o direito de procriar. In: CASTRO, Rodrigo Pironti Aguirre e outros. A advocacia iniciante e os novos rumos do direito - estudo aplicado. Curitiba: OAB/PR, 2006. t. 2, p. 350.

${ }^{5}$ GOODFIELD, June. Brincando de Deus - a engenharia genética e a manipulação da vida. Belo Horizonte: Itatiaia, 1994, p. 65. 


\section{PESQUISAS COM CÉLULAS-TRONCO EMBRIONÁRIAS E A CONVENÇÃO AMERICANA DE DIREITOS \\ HUMANOS - PACTO DE SAN JOSÉ DA COSTA RICA}

muito próximas uma da outra. ${ }^{6}$

Assim, o mundo acorda para o poder do advento de novos métodos, novas técnicas e do avanço da tecnologia. Estando em debate a questão ciência versus ética. O poder fazer absoluto, limitado pela natureza, contra o fazer ou não o que posso, tendo como limite à própria consciência. ${ }^{7}$

E ainda nas palavras do Dr. Erwin Chargaff, que denominou esses estudos de a Doutrina do Diabo: "O que pode ser feito deve ser feito". 8

De acordo com Genival Veloso de França, agora, como sempre - mas, hoje, muito mais do que antes, a consciência atual, despertada pela insensibilidade e pela indiferença do mundo tecnicista, começa, pouco a pouco, a se reencontrar com a mais primária e indeclinável de suas normas: o respeito pela vida humana. ${ }^{9}$

Conquanto, a análise parte de consagrar o embrião como vida humana ou não. Contudo, para se falar de embriões há que se debruçar em sua origem. De modo, não há como falar em pesquisas com células-tronco, sem antes mencionar de onde surgem os embriões previstos na Lei $\mathrm{n}^{\mathrm{o}}$ 11.105/05.Portanto, o ponto de partida deste estudo depreende-se das técnicas de Reprodução Humana Medicamente Assistida.

Com o advento das técnicas e aprimoramento das tecnologias não se tem mais apenas à cópula carnal como única forma de concepção e muito menos o casamento como único meio de criação da família.

De modo que novos paradigmas são criados, com o intuito de criar novas possibilidades, a fim de "driblar" a impossibilidade de procriação natural. ${ }^{10}$ Para isso as ciências médicas oferecem várias técnicas. Dentre elas pode-se classificar em dois

${ }^{6}$ Ibidem, p.72.

${ }^{7}$ GRACIANO, op. cit., p. 349.

${ }^{8}$ GOODFIELD, op. cit., p. 20.

${ }^{9}$ FRANÇA, Genival Veloso de. Aborto: breves reflexões sobre o direito de viver. Disponível em: <http://www.montfort.org.brelanca_celulastronco> Acesso em: 30 jun. 2006.

10 SAUWEN, Regina; HRYNIEWICZ, Severo. O direito “in vitro": da bioética ao biodireito. Rio de Janeiro; Lumen Juris, 1997, p. 76. 
grandes gêneros: Inseminação artificial e a Fertilização in vitro.

A primeira consiste na introdução do esperma na cavidade uterina ou no canal cervical, por meio de uma cânula. ${ }^{11}$

Já fertilização in vitro, baseia-se em retirar um ou vários óvulos de uma mulher, fecundá-los em laboratório, e depois realizar a transferência ao útero ou às trompas de Falópio. ${ }^{12}$

Ambas as técnicas podem ser homólogas e heterólogas. Esta quando há doação (doador anônimo) de material genético (óvulo ou sêmen) e aquela, quando não há doação do material genético.

Sendo assim, os métodos artificiais de Reprodução Humana Medicamente Assistida são o gênese dos embriões, mas precisamente a técnica de Fertilização in vitro.

Nesta técnica a ovulação é induzida por hormônios, com o intuito de produzir vários óvulos, para serem coletados e reunirem maiores condições de êxito.

Ocorre que muitos desses óvulos são coletados, fertilizados e não são implantados. Surge assim a problemática do embrião excedentário, ou seja, aqueles que não foram transferidos.

E não foram transferidos em duas hipóteses, uma porque não eram "normais", duas porque ultrapassaram o limite máximo para implantação. ${ }^{13}$

Desta feita, surge o impasse. Sobraram embriões, ou porque, foram coletados e nem todos foram transplantados, a fim de evitar os riscos à mãe, ou de aborto decorrente de gestação múltipla, ou porque, poderia provocar parto precoce, ou ainda, porque este embrião é inviável, ou seja, possui alguma anomalia cromossômica.

${ }^{11}$ SCARPARO, Mônica Sartori. Fertilização assistida; questão aberta: aspectos científicos e legais. Rio de Janeiro: Forense Universitária, 1991, p. 10.

${ }^{12}$ Ididem, p. 11.

13 De acordo com a Resolução do Conselho Federal de Medicina 1358/92 no item I, no 6 seriam transferidos no máximo quatro. De acordo com o Projeto de Lei 90/99 seriam também quatro, e ainda de acordo com o substitutivo a este Projeto de Lei prevê a coleta e transferência de dois, o que 


\section{PESQUISAS COM CÉLULAS-TRONCO EMBRIONÁRIAS E A CONVENÇÃO AMERICANA DE DIREITOS HUMANOS - PACTO DE SAN JOSÉ DA COSTA RICA}

Percebe-se assim, que por um motivo, ou outro, não são implantados. Surge assim a preocupação ética, jurídica e social do embrião excedentário, e afinal qual o seu destino?

No intuito, de a priori, evitar a destruição, ${ }^{14}$ de acordo com a Resolução 1.358/92 do Conselho Federal de Medicina, ${ }^{15}$ estes são criopreservados, ou seja, congelados em nitrogênio $-196^{\circ}$, e dados revelam que a taxa de sobrevida seria em torno de $75 \% .^{16}$

A criopreservação possibilitaria a sua futura utilização, sendo implantado no útero pelo casal do projeto parental, para doações, para uso em pesquisas científicas para identificar anomalias cromossômicas ou genéticas. ${ }^{17}$

Observa-se que, aparentemente ter-se-ia solução para o embrião não implantado, visto que seu o descarte é vedado pela Resolução do Conselho Federal de Medicina.

Entretanto, numa análise mais profunda verificam-se os seguintes problemas desta criopreservação.

Primeiro, como saber o prazo adequado para mantê-lo congelado? E quais os riscos para o embrião após ser descongelado? São impasses presentes e as respostas científicas calam.

A Resolução do Conselho Federal de Medicina nada prevê, apenas menciona que podem ser transferidos a fresco ou então congelados, mas nada fala por quanto tempo. Entretanto, agora no Brasil, de acordo com o previsto no artigo $5^{\mathrm{o} 18}$ da Lei $n^{\circ}$

não ensejaria embriões excedentários.

14 A destruição de embriões pré-implantatórios é vedada pela Resolução 1.358/92 (inciso V, 2), do Conselho Federal de Medicina.

${ }^{15}$ Destaca-se que a Resolução 1.358/92 Conselho Federal de Medicina não tem força cogente, trata-se tão-somente de parâmetros éticos a serem seguidos pelos médicos.

${ }^{16}$ SANTOS, Maria Celeste Cordeiro Leite dos Santos. Imaculada Concepção: nascendo in vitro e morrendo in machina. São Paulo: Acadêmica, 1993, p. 115.

${ }^{17}$ LEITE, Eduardo de Oliveira. Procriações artificiais e o direito. São Paulo: RT, 1995, p. 163.

${ }^{18}$ Art. 5" "É permitida, para fins de pesquisa e terapia, a utilização de células-tronco 
11.105/2005 depreende-se que seriam três anos, pois a partir deste lapso temporal, o embrião já preenche as condições para ser "utilizado" para fins de pesquisa e terapia.

A criopreservação não se preocupa com a natureza do embrião, se seria humana, ou não, pois ao passo que possibilita ao casal deliberar sobre o uso, o congelamento, o momento oportuno, a doação, acaba por “coisificá-lo". 19

E neste mesmo sentido, a Lei $n^{\circ} 11.105 / 2005$ (Lei de Biossegurança), não pondera se o embrião possui ou não condição humana, apenas viabiliza e legaliza a prática da sua utilização para pesquisas e fins terapêuticos.

Ressalta-se que não existe qualquer critério científico que embase o estabelecimento do período de três anos. Acresce, novamente, a ausência de critérios relativos à coleta dos embriões, deixando-se em aberto a questão de saber o que são “embriões inviáveis" e, se "inviáveis", inviáveis para o quê. ${ }^{20}$

O homem, ao ampliar o seu domínio sobre a natureza, intervém na sua própria condição natural de pessoa e possibilita a implantação de tecnologias sem previsão quanto às suas conseqüências. Por lidar com esse novo tipo de conhecimento, o homem contemporâneo interroga-se de forma crescente sobre as dimensões, as repercussões e as perspectivas das novas descobertas científicas e de suas aplicações tecnológicas. $^{21}$

Entre os valores inerentes à condição humana está a vida. Embora a sua origem permaneça um mistério, tendo-se conseguido, no máximo, associar elementos que a produzem ou saber que em certas condições ela se produz, o que se tem como

embrionárias obtidas de embriões humanos produzidos por fertilização in vitro e não utilizados no respectivo procedimento, atendidas as seguintes condições: I - sejam embriões inviáveis; ou, II sejam embriões congelados há 3 (três) anos ou mais, na data da publicação desta Lei, ou que, já congelados na data da publicação desta Lei, depois de completarem 3 (três) anos, contados a partir da data de congelamento".

${ }^{19} \mathrm{O}$ termo apresenta-se entre aspas para identificar o caráter equivocado que se dá em relação ao embrião.

${ }^{20}$ MARTINS, Costa Judith; GOLDIN José Roberto. Lei de biossegurança - medusa legislativa? Jornal da ADUFRGS, n. 134, p. 19-21, maio 2005.

${ }^{21}$ BARRETTO, Vicente de Paulo. Bioética, biodireito e direitos humanos. Disponível em: <http://www.dhnet.com.br> Acesso em: 1 jul. 2006. 
certo é que sem ela a pessoa humana não existe como tal, razão pela qual é de primordial importância para a humanidade o respeito à origem, à conservação e à extinção da vida. $^{22}$

Destarte, toda celeuma debruça-se em conferir ao embrião a condição de ser humano, ou não, e valorá-lo como pessoa e conseqüentemente reconhecer-lhe o direito à vida.

Primeiramente pretender-se-á definir do que, ou, de quem se trata o embrião, iniciando-se a partir do seu desenvolvimento.

\section{A ORIGEM DO EMBRIÃO}

Como apresentado, a questão debruça-se na análise se o referido embrião é ou não, um ser humano, aliás, mais que ser humano, se se trata de pessoa. Para tanto, inicia-se da análise do começo da vida.

Atualmente, apesar de todos os descobertas e avanços tecnológicos, o início da vida aparece aos olhos humanos e científicos não menos admirável, nem menos enigmático que há milênios e, apesar disso, muitos cientistas se julgam aptos suficientemente esclarecidos para estabelecer critérios sobre os limites da vida, sobre o seu inicio e fim, atrás de um tecnicismo que se esconde à dificuldade de aceitar sua própria limitação. $^{23}$

O óvulo e os espermatozóides estão vivos, contudo enquanto não ocorrer à fusão dos prónucleos serão distintamente apenas material genético feminino e masculino, respectivamente, que servirão para formação do novo ser, qual seja o

${ }^{22}$ DALLARI, Dalmo de Abreu Dallari. Bioética e direitos humanos. Disponível em: $<$ http//:www.dhnet.com.br> Acesso em: 22 jul. 2006.

${ }^{23}$ SIQUEIRA, Marília. O início da vida e a medicina atual. In: PENTEADO, Jaques de Camargo e outros. A vida dos direitos humanos - bioética médica e jurídica. Porto Alegre: Fabris, 1999. p. 335. 
embrião.

Por meio dos vários estudos científicos tornou-se possível afirmar a existência das distintas fases do desenvolvimento humano, desde a concepção até o nascimento. Porém, a ciência não pode determinar exatamente uma passagem da animalidade à humanidade, um limite que uma vez transposto, determine a natureza humana. ${ }^{24}$

Para teoria genético-desenvolvimentista até, a $8^{\mathrm{a}}$ semana $\mathrm{o}$ embrião não apresenta características para identificá-lo como pessoa.

Dentre os elementos capazes de determinar a sua individualidade; pode-se destacar: a fecundação: fusão dos prónucleos - zigoto; $2^{\circ}$ a $3^{\circ}$ dias $1^{a}$ divisão mitótica - mórula; $4^{\circ}$ a $5^{\circ}$ dias blastoceles - este é o momento que são totipotentes, ou seja, pode exprimir cada uma o programa genético completo de um indivíduo humano; $6^{\circ}$ dia interação como corpo materno; $7^{\circ}$ ao $12^{\circ}$ dia implantação e formação da membrana (cifra de ouro); após $18^{\circ}$ dia placa neural.

Durante as oito primeiras semanas de seu desenvolvimento trata-se de um embrião. A questão chave é se este ser é humano já pode ser considerado uma pessoa ou não. Se for considerado pessoa, merece todo respeito e reconhecimento da sua dignidade, em caso contrário, não. ${ }^{25}$

Foi no Relatório de Warnock que o termo pré-embrião foi apresentado no sentido se não considerá-lo pessoa, o que possibilita as pesquisas, entretanto só até o $14^{\circ}$ dia.

Os defensores desta teoria visualizam no embrião um antes e um depois na aquisição da dignidade humana, entretanto para Eduardo Oliveira Leite isso é inadmissível juridicamente. ${ }^{26}$

A respeito do termo pré-embrião o professor de genética humana Jérôme

${ }^{24}$ ALVES, João Evangelista dos Santos. Direitos humanos, sexualidade e integridade na transmissão da vida. In: PENTEADO, Jaques de Camargo e outros. A vida dos direitos humanos bioética médica e jurídica. Porto Alegre: Fabris, 1999. p. 214-215.

${ }^{25}$ GOLDIN, José Roberto. O que é o embrião. In: KIPPER, Décio José e outros. Ética em pesquisa: reflexões. Porto Alegre: EDIPUCRS, 2003. p. 55.

${ }^{26}$ LEITE, op. cit., p. 385. 


\section{PESQUISAS COM CÉLULAS-TRONCO EMBRIONÁRIAS E A CONVENÇÃO AMERICANA DE DIREITOS \\ HUMANOS - PACTO DE SAN JOSÉ DA COSTA RICA}

Lejeune, observou:

Cada ser humano tem começo único, que ocorre no momento da concepção. Embrião: '...Essa a mais jovem forma do ser...' Pré-embrião: essa palavra não existe. Não há necessidade de uma subclasse de embrião a ser chamada de pré-embrião, porque nada mais existe antes do embrião; antes do embrião existe apenas um óvulo e o esperma; quando o óvulo é fertilizado pelo espermatozóide a entidade assim constituída se transforma em um zigoto; e quando o zigoto se subdivide torna-se em embrião. Desde a existência da primeira célula todos os elementos individualizadores para transformá-lo num ser humano já estão presentes, logo um `pequeno ser humano já existe' ${ }^{27}$

Há ainda outras teorias que consideram o início da vida humana a partir de diversos dados, a citar: a Teoria da Configuração dos órgãos; a Teoria sexual; a Teoria da Formação do sistema nervoso; a Teoria da viabilidade; a Teoria da infusão da alma.

De qualquer forma, as teorias baseiam-se em dados meramente cronológicos, portanto o critério científico é variável, o que torna impreciso dizer ser um critério o certo e o outro o errado. Entretanto, a fecundação torna-se a mais aceitável, pois as demais fases dependem da fecundação, assim as demais teorias dependem da ocorrência da fecundação, porque esta é o início do novo ser único geneticamente.

Assevera Dernival da Silva Brandão, "Cada fase exige e compreende a fase anterior e determina a fase seguinte". 28

O fato é que, no embrião acham-se fundidas as células germinais humanas, responsáveis pelo início da vida, cujo novo ser possui a partir da fecundação, caracteres genéticos indiscutivelmente humanos, próprios, irrepetíveis e insubstituíveis com capacidade de desenvolver-se até converter-se em um homem. ${ }^{29}$

Tem-se a fecundação como início do ciclo vital. Nas palavras de Jussara

${ }^{27}$ DINIZ, Maria Helena. O estado atual do biodireito. 2. ed. São Paulo: Saraiva, 2002, p. 427-428.

${ }^{28}$ BRANDÃO, Dernival da Silva. O embrião e os direitos humanos. O aborto terapêutico. In: PENTEADO, Jaques de Camargo e outros. A vida dos direitos humanos - bioética médica e jurídica. Porto Alegre: Fabris, 1999. p. 13.

${ }^{29}$ MACHADO, Maria Helena. Reprodução humana assistida - aspectos éticos \& jurídicos. Curitiba: Juruá, 2003, p. 86. 
Meirelles:

A fecundação do óvulo humano assinala o começo da vida de cada indivíduo, distinto daqueles que contribuíram biologicamente para sua formação e dotado de um código genético próprio que conduzira todo seu desenvolvimento. Essa noção de autonomia possibilitou à corrente doutrinária denominada concepcionista sustentar que o embrião humano caracteriza-se como pessoa a partir da concepção. ${ }^{30}$

Concepção é sinônimo de fecundação, com individualização de material, já dotado de vida com elemento genético próprio, então possui similitude com o ser humano nascido, mesmo que ainda não seja sujeito de direitos. ${ }^{31}$

O início da vida, tem-se que "não é a mãe que faz a criança, mas é a própria criança que se faz no ecossistema que é a mãe". ${ }^{32}$ Portanto, dizer que a criança faz parte da mãe é erro científico.

Para parte da doutrina, o embrião goza de dignidade humana, primeiro porque se trata de um ser individualizado, não se trata de parte da mãe, possui autonomia vital, organização celular própria e única, com funções próprias.

De modo que, há autonomia do embrião - carga genética própria, ocorre no corpo, apenas processo de desenvolvimento. Desta feita, é pertencente à espécie humana desde a fecundação.

Entretanto, a temática não tem posicionamento unívoco, e em sentido contrário, Yglesias Perolo, o óvulo fecundado fora do útero não tem a mesma relevância jurídica que um embrião em processo de desenvolvimento no ventre. ${ }^{33}$

Neste mesmo paralelo, apenas para citar a lei brasileira $n^{\circ} 9.434 / 1997^{34}$ que

${ }^{30}$ MEIRELLES, Jussara Maria de Leal. A vida humana embrionária e a sua proteção jurídica. Rio de Janeiro: Renovar, 2000, p. 91.

${ }^{31}$ Ibidem, p.11.

${ }^{32}$ SILVA apud MEIRELLES, op. cit., p. 100.

${ }^{33}$ PEROLO apud MEIRELLES, op. cit., p. 105.

${ }^{34}$ Lei Federal 9.434/1997 art. $3^{\circ}$ "A retirada post mortem de tecidos, órgãos ou partes do corpo humano destinados a transplante ou tratamento deverá ser precedida de diagnóstico de morte encefálica, constatada e registrada por dois médicos não participantes das equipes de remoção e 


\section{PESQUISAS COM CÉLULAS-TRONCO EMBRIONÁRIAS E A CONVENÇÃO AMERICANA DE DIREITOS HUMANOS - PACTO DE SAN JOSÉ DA COSTA RICA}

regulamenta os transplantes, condiciona a existência ou não de vida à atividade cerebral.

Ressalve-se que aqui em nenhum momento se pretende a comparação do embrião com órgãos, ou tecidos, mas tão-somente apresentar mais um critério que define a existência ou não de vida num ser humano.

Nesse sentido Márcia Regina Machado Melaré, “A vida no ser humano existe somente se as funções cardíacas e cerebrais estão em funcionamento simultâneo e regular". 35

Entretanto, pontua June Goodfield em seu livro Brincando de Deus:

Toda essa série de preocupações se concentra na questão de se saber exatamente o que significa pertencermos ao gênero humano e qual o tipo de humanidade que estamos dispostos a defender. Se todas as tecnologias deste Admirável Mundo Novo se tornarem viáveis - o que pode acontecer — e forem aplicadas — o que talvez não aconteça — que tipo de homem teremos criado $?^{36}$

De acordo com a Dra . Mayana Zatz, cientista Coordenadora do Centro de Estudos do Genoma Humano da Universidade de São Paulo - USP, a vida seria um ciclo, verbis:

A ciência tem uma visão, que eu acho bastante interessante, segundo a qual não existe começo ou fim: a vida seria um ciclo. Ou seja, um embrião se forma, se desenvolve e um dia vai produzir células germinativas que vão originar um novo ser. Levando em conta esta filosofia, para um embrião congelado, que não tem qualidade para formar uma vida, o ciclo acabou. Mas se, a partir deste embrião, forem extraídas células-tronco que podem curar, por exemplo, uma criança acometida por uma doença letal, estaremos mantendo o ciclo da vida. $^{37}$

transplante, mediante a utilização de critérios clínicos e tecnológicos definidos por resolução do Conselho Federal de Medicina".

${ }^{35}$ MELARÉ, Márcia Regina Machado. Direito à vida: sim às pesquisas com células-tronco embionárias. Revista Consultor Jurídico, 2 mar. 2005. Disponível em: <http://conjur.estadao.com.br/static/text/33284,1> Acesso em: 7 set. 2006.

${ }^{36}$ GOODFIELD, op.cit., p. 54.

${ }^{37}$ ZATZ, Mayana. Entrevista à Folha Online em 13.03.04. Coordenadora do Centro de Estudos do Genoma Humano da USP. In: MEDEIROS, Leonardo. Cientista da USP defende 
Diante dessas premissas, percebe-se que não existe um único critério identificador do início da vida. De modo que adotando a teoria da fecundação para estabelecer o inicio da vida, pode-se dizer que a natureza do embrião como ser humano estará sendo reconhecida, mas não necessariamente a sua condição de pessoa.

Contudo, cabe agora identificar se também existe o seu reconhecimento como pessoa, e conseqüentemente o seu reconhecimento como sujeito de direitos, dentre eles 0 direito à vida.

\section{CONSIDERAÇÕES SOBRE A PESSOA HUMANA}

A preocupação, em considerá-lo como pessoa é justamente afastar qualquer possibilidade de identificá-lo como bem, ou como coisa, ainda que localizado em laboratório.

Portanto, para teoria concepcionalista não haveria diferença do local em que ocorre, se in vitro ou em laboratório. O começo a vida de cada indivíduo dar-se-ia com a fecundação, este distinto e com código genético próprio.

Assim, esse posicionamento entende que o embrião, mesmo que não transferido para o útero, é uma pessoa, mesmo que não tenha capacidade. Portanto, não pode ser objeto, mas sujeito de direitos. Sendo ilícitos quaisquer atos que impliquem na sua disponibilidade, como previstos na Lei $\mathrm{n}^{\mathrm{o}} 11.105 / 2005$ - Lei de Biossegurança.

A natureza do embrião, já como explanado, se adotada a teoria da fecundação como o início da vida, é a de ser humano. E deste modo, por se tratar de ser humano, há valores que lhe são correlatos.

Entretanto, neste sentido, cabe a reflexão, se o valor da pessoa humana pode

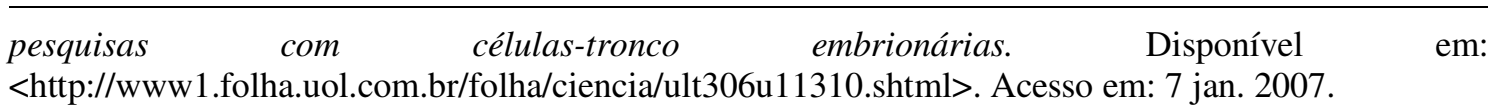




\section{PESQUISAS COM CÉLULAS-TRONCO EMBRIONÁRIAS E A CONVENÇÃO AMERICANA DE DIREITOS HUMANOS - PACTO DE SAN JOSÉ DA COSTA RICA}

ser afastado diante da realidade de se encontrarem em etapas bem iniciais de vida e criopreservados em laboratórios.

A definição de pessoa está subordinada a dados filosóficos com elementos de racionalidade e individualidade. Tem-se a noção clássica - indivíduo concreto, dotado de uma série de capacidades; e o conceito abstrato - conjunto de propriedades e funções. Pessoa conceito técnico-jurídico - categoria abstrata cuja finalidade é estabelecer parâmetros à titularidade jurídica (sujeito de direitos). ${ }^{38}$ Depreende-se que, pessoa é o centro de imputação de poderes, sendo que ser humano pode não ser pessoa, no sentido técnico-jurídico.

Ao passo que as pessoas em sentido jurídico não são necessariamente seres humanos, logo atribuição ou reconhecimento da personalidade é pressuposto lógico do Direito.

Considerando a caracterização do embrião humano como pessoa desde o momento da fecundação, o termo pessoa não está no sentido técnico-jurídico. De acordo com a corrente concepcionista, com contornos mais amplos, sob o enfoque da pessoa com valor moral, com proteção incondicionada. E nesta visão o embrião possui caráter humano ainda que em sentido amplo. A tese concepcionista busca o amparo dos embriões concebidos e conservados em laboratório, afirmando que desde a concepção existe vida humana.

Diante das inúmeras teorias, umas que admitem a qualidade humana e outras que refutam completamente, há outra teoria eclética - sem classificar o embrião como ser humano desde a concepção, mas não afastando a idéia referente à possibilidade de "vir a se tornar humano."

A Teoria da Potencialidade considera não ser possível identificar o embrião como ser humano, pois este é dotado de personalidade, e nem apenas um aglomerado de celular, pois o seu desenvolvimento leva a um ser humano.

Desta feita, reconhece o embrião como um ser humano em potencial, e que

${ }^{38}$ MEIRELLES, op. cit., p. 93-95. 
estaria num estado de latência. Que iria se aperfeiçoar no direito e dever de gerar o embrião de forma autenticamente responsável.

Os defensores de uma ontologia progressiva costumam asseverar que o ser embrionário é um ser em desenvolvimento e que, perante uma célula viva, depois um feto de cinco meses, depois uma criança de cinco anos, as obrigações morais não podem ser as mesmas, as prerrogativas humanas ampliam-se proporcionalmente ao desenvolvimento de ser que se forma. ${ }^{39}$

Quando se afirma que o embrião deve ser tratado como uma pessoa em potencial, duas premissas são abordadas. Uma, de que não é possível considerá-lo como uma pessoa atual, capaz de valer sua dignidade. A segunda, de que ao falar em pessoa potencial implica respeitar não mais que uma potencialidade de ser humano, trata-se de impor respeito dentro dos limites do que o novo ser representa, ou seja, uma pessoa potencial. $^{40}$

Em relação a essa potencialidade manifestou-se Márcia Regina Machado Melaré no seguinte sentido: "A vida real ficará marginalizada pela inexistente potencialidade de vida dos blastocistos não implantados no ventre materno". 41

Merecem destaque as considerações de Jussara Maria Leal de Meirelles:

Quando se trata de embriões para pesquisas, pode-se dizer que não é tanto o direito de sacrificar embriões humanos para pesquisas que é discutível, mas sim o direito, através de tecnologias nascidas dessas pesquisas, de assumir o risco de alterar de modo imprevisível a qualidade de existência das gerações futuras. ${ }^{42}$

Partindo dessas colocações, observa-se que não existe uma convicção unânime, nem do início da vida e muito menos de quando o ser humano é valorado como pessoa, o que se tem são teorias e doutrinas que embasam ambos os

${ }^{39}$ SÈVE apud MEIRELLES, op. cit., 2000, p. 146.

${ }^{40}$ Ibidem, p. 147.

${ }^{41}$ MELARÉ, op. cit.

${ }^{42}$ MEIRELLES, op. cit., p. 142. 
PESQUISAS COM CÉLULAS-TRONCO EMBRIONÁRIAS E A CONVENÇÃO AMERICANA DE DIREITOS

HUMANOS - PACTO DE SAN JOSÉ DA COSTA RICA

posicionamentos. No entanto, justamente por não se ter uma definição exata do estatuto jurídico do embrião, é que as pesquisas que envolvem as células-tronco embrionárias causam tanta polêmica, e a comunidade científica e jurídica buscam resolver esse impasse.

Para tanto, a fim de controbuir com algumas reflexões sobre a temática, dedicar-se-á a analisar a Convenção Interamericana de Direitos Humanos, especificamente o Pacto de San José de Costa Rica, no que se refere à proteção do direito à vida.

\section{O DIREITO À VIDA NA CONVENÇÃO AMERICANA DE DIREITOS HUMANOS -PACTO DE SAN JOSE DA COSTA RICA}

Os direitos humanos fundamentais têm como propósito assegurar o mínimo de direitos, a promoção de condições dignas de vida humana e de seu desenvolvimento, assim como, garantir a defesa dos seres humanos contra abusos de poder econômico cometidos pelos órgãos do Estado. E justamente para que esse mínimo seja preservado existe a necessidade de instrumentos que viabilizem a implementação desses direitos, submetendo os Estados a essa interferência.

De acordo com Antônio Trindade:

O processo de generalização da proteção dos direitos humanos desencadeou-se no plano internacional a partir da adoção em 1948 das Declarações Universal e Americana dos Direitos Humanos. Era preocupação corrente, na época, a restauração do direito internacional em que viesse a ser reconhecida a capacidade processual dos indivíduos e grupos sociais no plano internacional. Para isto contribuíram de modo decisivo as duras lições legadas pelo holocausto da segunda guerra mundial. ${ }^{43}$

Nas palavras de Flávia Piovesan: "A universalização dos direitos humanos fez

${ }^{43}$ TRINDADE, Antônio Augusto Cançado. A proteção internacional dos direitos humanos e o Brasil (1948-1997): as primeiras cinco décadas. 2. ed. Brasília: UnB, 2000, p. 23. 
com que os Estados consentissem em submeter ao controle da comunidade internacional, mediante a criação de uma sistemática internacional de monitoramento e controle". ${ }^{44}$

Buscando a efetividade e o reconhecimento de direitos humanos mínimos, inicia-se um processo de juridicização. A partir do Pacto Internacional de Direitos Econômicos, Sociais e Culturais; e do Pacto Internacional de Direitos Civis e Políticos, sendo que a partir da elaboração desses pactos se forma a Carta Internacional dos Direitos Humanos, International Bill of Rights, integrada pela Declaração de 1948 e pelos dois pactos. De forma que a comunidade internacional devesse tratar dos direitos humanos globalmente, de modo justo e eqüitativo, com o mesmo fundamento e a mesma ênfase. Surgindo assim o sistema de proteção em termos globais, o que significa dizer que esse sistema global não se limita a determinada região, podendo alcançar qualquer Estado-parte. ${ }^{45}$

No âmbito global as experiências de justicialização eram somente na esfera penal, alcançando indivíduos pautados em crimes. No entanto, os sistemas regionais têm caráter civil, alcançando não indivíduos, mas Estados, sendo os mesmos condenados por violações aos Direitos Humanos. ${ }^{46}$

Ao lado do sistema global, surge o sistema regional de proteção, este que tem o objetivo de internacionalizar os direitos humanos no plano regional, particularmente na Europa, América e África. Esses sistemas regionais buscam uma efetividade, facilitando as relações e os mecanismos de controle, e em geral ligados pelas peculiaridades culturais, lingüísticas. ${ }^{47}$

De acordo com Flávia Piovesan:

${ }^{44}$ PIOVESAN, Flávia. Direitos humanos e o direito constitucional internacional. São Paulo: Saraiva, 2006, p. 151.

\footnotetext{
${ }^{45}$ Ibidem, p. 152.

${ }^{46}$ Ibidem, p. 221.

${ }^{47}$ Idem.
} 


\section{PESQUISAS COM CÉLULAS-TRONCO EMBRIONÁRIAS E A CONVENÇÃO AMERICANA DE DIREITOS HUMANOS - PACTO DE SAN JOSÉ DA COSTA RICA}

Consolida-se, assim, a convivência do sistema global — integrado pelos instrumentos das Nações Unidas, como a Declaração Universal de Direitos Humanos, o Pacto Internacional dos Direitos Civis e Políticos, o Pacto Internacional dos Direitos Econômicos, Sociais e Culturais e as demais Convenções internacionais - com instrumentos do sistema regional de proteção, integrado por sua vez pelo sistema interamericano, europeu e africano de proteção aos direitos humanos. $^{48}$

Dentre tantos tratados, convenções, pactos, o objeto deste estudo debruça-se na Convenção Americana de Direitos Humanos, por se tratar de um sistema regional de proteção que busca internacionalizar os direitos humanos no plano regional, sendo de extrema relevância para o presente estudo o sistema interamericano, uma vez que se aplica diretamente ao caso brasileiro, que tem como principal instrumento a Convenção Americana de Direitos Humanos de 1969 que, por sua vez, estabelece a Comissão Interamericana de Direitos Humanos e a Corte Interamericana.

É pública e notória a discussão acerca do fundamento e da natureza dos direitos humanos, especialmente quando se questiona tratarem-se eles de direitos naturais e inatos, direitos positivos, direitos históricos ou direitos atrelados ao sistema moral. Os estudos contemporâneos inclinam-se pela historicidade dos direitos humanos, uma vez que esses se constituem num processo constante de construção e aperfeiçoamento de si mesmos.

Segundo as lições de Norberto Bobbio extrai-se que "os direitos do homem nascem como direitos naturais universais, desenvolvem-se como direitos positivos particulares, para finalmente encontrarem sua plena realização como direitos positivos universais". 49

Inicialmente pode-se afirmar que os $\operatorname{tratados}^{50}$ internacionais, como acordos internacionais juridicamente obrigatórios e vinculantes (pacta sunt servanda),

\footnotetext{
48 PIOVESAN, op. cit., p. 222.
}

49 BOBBIO, Norberto. A era dos direitos. Trad. Carlos Nelson Coutinho. Rio de Janeiro: Campus, 1992, p. 30.

50 Tratados no sentido do gênero, do qual sai espécies as convenções, pactos, carta, protocolo, convênio, acordo. 
constituem hoje a principal fonte de obrigação do direito internacional. ${ }^{51}$

Aprovada na Conferência de São José da Costa Rica em 22 de novembro de $1969,{ }^{52}$ a Convenção reproduz a maior parte das declarações de direitos constantes do Pacto Internacional de Direitos Civis e Políticos de 1966, a Convenção aproxima-se mais do modelo da Convenção Européia de Direitos Humanos de 1950. ${ }^{53}$

A fim de obter a adesão dos Estados Unidos à Convenção, a Conferência de São José da Costa Rica decidiu deixar para um Protocolo à parte a declaração de direitos econômicos, sociais e culturais; Protocolo esse que só veio a ser aprovado na Conferência Interamericana de São Salvador, em 17 de novembro de 1988. Igualmente objeto de um Protocolo adicional à Convenção é o acordo sobre a abolição da pena de morte, obtido na Conferência Interamericana de Assunção, em 8 de junho de 1990. Este último Protocolo reproduz, para os Estados americanos, as disposições do Segundo Protocolo Facultativo ao Pacto sobre Direitos Civis e Políticos de $1966 .{ }^{54}$

O Brasil aderiu à Convenção em 1992, umas das regras inerentes aos Tratados está em que os Tratados não podem criar obrigações para os Estados que neles não consentirem, desta feita uma vez que é incorporado deve ser cumprido e boa-fé, e ainda os tratados são expressões consensuais.

Esta convenção é mais extensa que muitos instrumentos internacionais de direitos humanos, destacam-se direitos como, o direito à personalidade jurídica, o

${ }^{51}$ PIOVESAN, op. cit., p. 43

52 O Brasil aderiu à Convenção por ato de 25-9-1992, ressalvando, no entanto a cláusula facultativa do art. $45,1^{\text {a }}$, referente à competência da Comissão Interamericana de Direitos Humanos para examinar queixas apresentadas por outros Estados sobre o não-cumprimento das obrigações impostas pela Convenção, bem como a cláusula facultativa do art. 62,1 , sobre a jurisdição obrigatória da Corte Interamericana de Direitos Humanos. A Convenção foi promulgada no Brasil pelo Decreto $\mathrm{n}$. 678, de 6 de novembro do mesmo ano. Pelo Decreto Legislativo n. 89, de dezembro de 1998, o Congresso Nacional aprovou "a solicitação de reconhecimento da competência obrigatória da Corte Interamericana de Direitos Humanos para fatos ocorridos a partir do reconhecimento, de acordo com o previsto no parágrafo primeiro do art. 62 daquele instrumento internacional". Pelo Decreto n. 4.463, publicado em 11-11-2002, foi promulgada essa declaração de reconhecimento da competência obrigatória da Corte.

${ }^{53}$ COMPARATO, Fábio Konder. A afirmação histórica dos direitos humanos. 3. ed. São Paulo: Saraiva, 2003, p. 362.

\footnotetext{
${ }^{54}$ Ibidem, p. 363.
} 


\section{PESQUISAS COM CÉLULAS-TRONCO EMBRIONÁRIAS E A CONVENÇÃO AMERICANA DE DIREITOS}

HUMANOS - PACTO DE SAN JOSÉ DA COSTA RICA

direito à vida, o direito de não ser submetido à escravidão, o direito à liberdade, o direito a um julgamento justo, o direito à compensação em caso de erro judiciário, o direito à privacidade, o direito à liberdade de consciência e religião, o direito à liberdade de pensamento e expressão, o direito à resposta, o direito à liberdade de associação, o direito ao nome, o direito à nacionalidade, o direito à liberdade de movimento e residência, o direito de participar do governo, o direito à igualdade perante a lei e o direito à proteção judicial.

A Convenção Americana não enuncia de forma específica qualquer direito social, cultural ou econômico; limita-se a determinar aos Estados que alcancem, progressivamente, a plena realização desses direitos, mediante a adoção de medidas legislativas e outras que se mostrem apropriadas nos termos do art. 26 da Convenção. Posteriormente, em 1988, a Assembléia Geral da Organização dos Estados Americanos adotou um Protocolo Adicional à Convenção, concernente aos direitos sociais, econômicos e culturais (Protocolo de San Salvador, que entrou em vigor em novembro de 1999, por ocasião do depósito do 11 instrumento de ratificação, nos termos do art. 21 do Protocolo).

De acordo com os direitos constantes da Convenção Americana, cabe ao Estado-parte a obrigação de respeitar e assegurar o livre e pleno exercício desses direitos e liberdades, sem qualquer discriminação. Cabe ainda, ao Estado-parte adotar todas as medidas legislativas e de outra natureza que sejam necessárias para conferir efetividade aos direitos e liberdades enunciados. ${ }^{55}$

O artigo $4^{\circ}$ do Pacto de San José da Costa Rica prevê que o direito à vida deve ser protegido pela lei desde o momento da concepção, vedando assim a legalização do aborto.

$\mathrm{O}$ artigo $4^{\circ}$ prevê que o direito à vida deve ser protegido pela lei e, em geral, a partir do momento da concepção, ou seja, leia-se desde a fecundação.

Ives Gandra da Silva Martins comenta a expressão em geral, no sentido de que alguns pretendem ler no vocábulo "em geral" uma relativização do dispositivo. 
Entretanto, para o autor é uma interpretação equivocada, e não corresponde a um dispositivo de direito internacional. Neste sentido, o artigo em menção estaria dividido em três partes. 1) toda a pessoa humana tem (presente do indicativo) direito a que se respeite a sua vida; 2) a lei protegerá (futuro) o direito a partir do momento da concepção, podendo fazê-lo de forma expressa (é o mais comum e o geral das vezes), mas, poderá omitir-se a expressa menção; 3) a vida do ser humano (nascido ou nascituro) não pode ser (presente do indicativo) eliminada arbitrariamente. ${ }^{56}$

Segundo o mesmo autor há dois comandos normativos de caráter essencial; o respeito ao direito à vida (do nascituro e do nascido) e a vedação que o ser humano (nascituro ou nascido), seja privado de sua vida arbitrariamente. E há um comando, natureza formal, de que a lei deverá explicitar o princípio da garantia desde a concepção, que é o que ocorre em geral. ${ }^{57}$

E nesta visão, o autor afirma que em nenhum momento, o dispositivo permite a leitura de que a lei poderá retirar o direito à vida após a concepção, pois, de outra forma, o ser humano (nascituro) estaria sendo privado de sua vida arbitrariamente. Por esta razão, o comando normativo está no presente no que concerne ao respeito ao direito à vida e à vedação a sua retirada arbitrária (de nascituro e do nascido), aconselhando-se, no futuro indicativo, que a lei explicite, em nível de legislação interna, o sentido do pacto de San José, o que de resto já ocorre em geral, com os países signatários. ${ }^{58}$

Entretanto, em que pesem tão valiosas considerações, todas são voltadas ao nascituro, ou ainda, até mesmo ao nascido. E neste sentido, não se discute a proteção jurídica. No entanto, o cerne da questão é em relação ao embrião, no que difere do nascituro, pois este já está implantado no ventre materno, ao passo que o embrião necessariamente não, aliás, é justamente o embrião in vitro, que se faz necessário

${ }^{55}$ PIOVESAN, op. cit., p. 229.

${ }^{56}$ MARTINS, Ives Gandra da Silva. O direito do ser humano à vida. In: (coord.). Direito fundamental à vida. São Paulo: Quartier Latin. Centro de Extensão Universitária, 2005. p. 28.

${ }^{57}$ Ibidem, p. 29.

${ }^{58}$ Idem. 


\section{PESQUISAS COM CÉLULAS-TRONCO EMBRIONÁRIAS E A CONVENÇÃO AMERICANA DE DIREITOS HUMANOS - PACTO DE SAN JOSÉ DA COSTA RICA}

repensar o sentido do direito à vida, à luz dos direitos humanos.

Assim, o artigo $4^{\circ}$ do Pacto de San José tal como redigido proíbe o aborto e também, em princípio, as práticas de produção de embriões humanos para fins industriais (utilização de seus tecidos na fabricação de cosméticos, por exemplo), bem como da clonagem humana para finalidades não reprodutivas e, portanto, com destruição do embrião visando apenas sua produção e descarte.

Entretanto, uma exceção, de acordo com Fábio Konder Comparato, é de que seria eticamente admissível a essa regra geral proibitiva, parece ser a da obtenção de embriões clonados para tratamento de doenças neurodegenerativas do próprio sujeito $^{59}$.

E nesta mesma linha de raciocínio, encontram-se também os embriões criopreservados, e que permaneceriam congelados no laboratório ad eternum, a espera de um projeto parental viável. De modo que não se trata de dar "utilidade" ao embrião, e nem de ceifar uma vida, mas sim vislumbrar o direito à vida digna de pessoas acometidas por enfermidades.Não se trata de minimizar o direito à vida, muito pelo contrário, trata-se de sua ampliação, no sentido de propiciar vida com dignidade.

Ives Gandra entende que os tratados internacionais sobre direitos fundamentais, a lei suprema, a lei civil - todos, todos, todos - cuidam do direito à vida, como direito essencial e que deve ser salvaguardado desde a concepção. ${ }^{60}$

Para Jussara Maria Leal de Meirelles, ao reconhecer aos seres embrionários natureza com valor próprio da pessoa humana, toda e qualquer atividade prejudicial ao seu saudável desenvolvimento atinge o bem jurídico vida assegurado à sociedade. ${ }^{61}$

Vale ressaltar que a Convenção prevê aos seus Estados-partes não só deveres negativos de evitar agressão aos direitos ali previstos, mas também de positivamente

${ }^{59}$ COMPARATO, op. cit., 64.

${ }^{60}$ MELLO, Gustavo Miguez de. Direito fundamental à vida. In: SILVA, Ives Gandra da (coord.). Direito fundamental à vida. São Paulo: Quartier Latin. Centro de Extensão Universitária, 2005. p. 272.

${ }^{61}$ MEIRELLES, op. cit., p. 223. 
de adotar medidas que favoreçam, que viabilizem a sua aplicação.

E ainda, a Carta Constitucional Brasileira de 1988 inova ao incluir entre os direitos constitucionais protegidos os direitos enunciados nos tratados internacionais de que o Brasil seja signatário. Assim, esse processo de inclusão implica a incorporação pelo texto constitucional de tais direitos. ${ }^{62}$

A interpretação do sentido do termo Direitos Humanos deve se dar de modo amplo, pois vincula a ação diplomática brasileira, devendo ser respeitado em quaisquer acordos ou atos unilaterais, uma vez que implica a necessidade de o governo brasileiro colaborar com qualquer órgão estabelecido para monitorar a situação dos Direitos Humanos em sistemas de que o Brasil faça parte. ${ }^{63}$

Antônio Augusto Cançado Trindade ressalta que:

(...) no domínio da proteção dos direitos humanos, na atualidade, faz-se mister expressar no direito interno as conquistas do direito internacional, ao invés de se tentar projetar neste a medida do direito interno. Há que se reduzir a distância entre as esferas internacionalista e constitucionalista. Nesse contexto, é necessário buscar uma maior concordância e aproximação entre o direito internacional e o direito interno, conjugando-se a realidade interna com os meios de proteção internacional dos direitos humanos. ${ }^{64}$

Os direitos enunciados nos tratados de direitos humanos de que o Brasil é parte integram o elenco dos direitos constitucionais, conclui-se isso devido à interpretação sistemática e teleológica do Texto, especialmente em face da força expansiva dos valores da dignidade humana e dos direitos fundamentais, como parâmetros axiológicos a orientar a compreensão do fenômeno constitucional. ${ }^{65}$

A Constituição recepciona os direitos enunciados em tratados de que o Brasil seja parte, portanto integram o catálogo de direitos constitucionalmente previstos, o que justifica estender a esses direitos o regime constitucional conferido aos demais

${ }^{62}$ PIOVESAN, op. cit., p. 52.

${ }^{63}$ MORAES, Mabel Cristiane. A proteção dos direitos humanos e sua interação diante do princípio da dignidade da pessoa humana. Jus Navigandi, Teresina, a. 8, n. 157, 10 dez. 2003. Disponível em: <http://jus2.uol.com.br/doutrina/texto.asp?id=4607>. Acesso em: 22 jul. 2006.

${ }^{64}$ TRINDADE, op. cit., p. 68.

${ }^{65}$ PIOVESAN, op. cit., p. 52. 


\section{PESQUISAS COM CÉLULAS-TRONCO EMBRIONÁRIAS E A CONVENÇÃO AMERICANA DE DIREITOS HUMANOS - PACTO DE SAN JOSÉ DA COSTA RICA}

direitos e garantias fundamentais. ${ }^{66}$

Assim, confere-se a máxima efetividade aos princípios constitucionais, em especial ao artigo $5^{\circ} \$ 2^{\circ}$, ao entender que os direitos, qual sejam, os que tratam de direitos humanos, integram o rol de direitos constitucionalmente previstos.

Como dito, a Convenção prevê aos seus Estados-partes não só deveres negativos de evitar agressão aos direitos ali previstos, mas também de positivamente de adotar medidas que favoreçam, que viabilizem a sua aplicação.

Especificamente no caso do Brasil, os direitos enunciados nos tratados de direitos humanos de que o Brasil é parte integram o elenco dos direitos constitucionais, conclui-se isso devido à interpretação sistemática e teleológica do Texto, especialmente em face da força expansiva dos valores da dignidade humana e dos direitos fundamentais, como parâmetros axiológicos a orientar a compreensão do fenômeno constitucional. ${ }^{67}$

É dever do Estado, que tem por objetivo a realização do bem comum, o respeito e a proteção do bem comum. O direito surge, assim, como um instrumento de auxílio para a consecução deste fim. A exemplo do Estado, o direito também é uma decorrência da natureza humana e existe para o ser humano; a pessoa constitui o princípio e o fim do direito.

De acordo com o constante no principal instrumento do sistema interamericano, a princípio as pesquisas com células-tronco embrionárias seriam incompatíveis com o sistema, principalmente porque reconhece que todo ser humano é pessoa. Assim, se dá união, ou seja, concepção, fecundação, de gametas humanos, inevitavelmente desta fusão surgia um ser humano, logo pela convenção é pessoa. E ainda considerando que a convenção destaca a proteção desde a concepção, leia-se fecundação.

Portanto, independente desta fecundação ocorrer in vitro (laboratório), ou, no

\footnotetext{
${ }^{66}$ PIOVESAN, op. cit., p. 58

${ }^{67}$ Ibidem, p. 52.
} 
útero continua a ser o mesmo embrião. Desta feita, a problemática não está propriamente em identificá-lo como ser humano, ou não, mas sim na sua valorização como pessoa, o que pelas considerações feitas acerca do sistema interamericano seriam idênticas.

De modo, que em linhas gerais de acordo com a Convenção Americana de Direitos Humanos, qualquer prática que desrespeite a vida do ser humano, avilta, fere direitos humanos, e descumpre o artigo $4^{\circ}$ da Convenção.

Entretanto, existem outras colocações a serem feitas em relação ao sistema Interamericano, com base no protocolo de San Salvador, ${ }^{68}$ em relação aos artigos, 10, 18 e 22 que tratam respetivamente do direito à saúde, ${ }^{69}$ à proteção dos deficientes, ${ }^{70}$ à incorporação de outros direitos e ampliação dos direitos já reconhecidos, ${ }^{71}$ e principalmente considerando o próprio art. 11 do Pacto de San José da Costa Rica que trata da dignidade da pessoa humana. ${ }^{72}$

${ }^{68}$ São países signatários: Argentina, Bolívia, Brasil, Chile, Colômbia, Costa Rica, Equador, El Salvador, Guatemala, Haiti, México, Nicarágua, Panamá, Paraguai, Peru, República Dominicana, Suriname, Uruguai e Venezuela.

${ }^{69}$ Art. 10 "Direito à saúde: Toda pessoa tem direito à saúde, entendida como o gozo do mais alto nível de bem-estar físico, mental e social. A fim de tornar efetivo o direito à saúde, os Estados Partes comprometem-se a reconhecer a saúde como bem público e, especialmente, a adotar as seguintes medidas para garantir esse direito: atendimento primário de saúde, entendendo-se como tal a assistência médica essencial colocada ao alcance de todas as pessoas e famílias da comunidade”;

70 Art. 18 - "Proteção de deficientes: Toda pessoa afetada por diminuição de suas capacidades físicas e mentais tem direito a receber atenção especial, a fim de alcançar o máximo desenvolvimento de sua personalidade. Os Estados Partes comprometem-se a adotar as medidas necessárias para esse fim e, especialmente, a: a) Executar programas específicos destinados a proporcionar aos deficientes os recursos e o ambiente necessário para alcançar esse objetivo, inclusive programas trabalhistas adequados a suas possibilidades e que deverão ser livremente aceitos por eles ou, se for o caso, por seus representantes legais; b) Proporcionar formação especial às famílias dos deficientes, a fim de ajudá-los a resolver os problemas de convivência e convertê-los em elementos atuantes no desenvolvimento físico, mental e emocional destes; c) Incluir, de maneira prioritária, em seus planos de desenvolvimento urbano a consideração de soluções para os requisitos específicos decorrentes das necessidades deste grupo; d) Promover a formação de organizações sociais nas quais os deficientes possam desenvolver uma vida plena".

${ }^{71}$ Art. 22 "Incorporação de outros direitos e ampliação dos reconhecidos: Possibilidade de considerar outros direitos: Qualquer Estado Parte e a Comissão Interamericana de Direitos Humanos poderão submeter à consideração dos Estados Partes, reunidos por ocasião da Assembléia Geral, propostas de emendas com o fim de incluir o reconhecimento de outros direitos e liberdades, ou outras destinadas a estender ou ampliar os direitos e liberdades reconhecidos neste Protocolo".

${ }^{72}$ Art. 11 "Proteção da honra e da dignidade: Toda pessoa tem direito ao respeito da sua 


\section{PESQUISAS COM CÉLULAS-TRONCO EMBRIONÁRIAS E A CONVENÇÃO AMERICANA DE DIREITOS HUMANOS - PACTO DE SAN JOSÉ DA COSTA RICA}

Em relação à dignidade humana, tem-se que é um conceito jurídico indeterminado, com forte carga de abstração. A pessoa é um bem a ser protegido pelo Estado e a dignidade é o seu valor. Trata-se de princípio absoluto, que todo estatuto jurídico deve garantir. ${ }^{73}$

O ser humano diferencia-se dos demais seres vivos pela sua capacidade de amar, de reconhecer no outro a importância da existência, conduzindo ao entendimento de que a dignidade da pessoa humana pressupõe: 1) o imperativo da intangibilidade da vida e, em decorrência, o respeito à integridade física e psíquica das pessoas; 2) a consideração dos pressupostos materiais mínimos para a vida; 3) o respeito às condições mínimas de liberdade e convivência social igualitária e pacífica. ${ }^{74}$

Assim sendo, a partir de uma análise mais minuciosa, percebe-se outra compreensão do direito à vida prevista no artigo $4^{\circ}$, tendo em consideração o reconhecimento da dignidade como um direito humano, e ainda levando em consideração o processo de internacionalização dos Direitos Humanos, que visa justamente assegurar a dignidade humana e prevenir o sofrimento humano, e com base no protocolo de San Salvador que trata do direito à saúde, da incorporação de outros, e também porque prevê proteção especial aos deficientes, inclusive para que o Estado promova medidas para desenvolver uma vida plena.

De sorte que as pessoas acometidas por limitações decorrentes de doenças que comprometam seu pleno desenvolvimento, ou seja, que a sua vida plena esteja comprometida, de acordo com o Pacto merece atenção especial.

Portanto, o Estado adotando medidas que vislumbrem propiciar melhores condições de vida, atende a essência de qualquer tratado, qual seja, de dar proteção à pessoa, garantindo-lhe vida com qualidade e alcançar a dignidade.

E ainda, no caso do sistema interamericano o Protocolo de San Salvador reconhece a possibilidade do reconhecimento de outros direitos, e de ampliação dos

honra e ao reconhecimento de sua dignidade".

\footnotetext{
${ }^{73}$ PINTO, 2006, p. 58.

${ }^{74}$ Idem.
} 
reconhecidos de modo que a interpretação do direito à vida, ultrapassa o reconhecimento da não ausência de vida, ou à morte, mas em conferir uma vida com dignidade, a fim de possibilitar uma melhor qualidade de vida, e amplia a visão do direito à saúde.

Destarte, como já relatado, os avanços da biotecnologia, mais especificamente as pesquisas com células-tronco embrionárias trazem uma nova realidade e conseqüentemente a necessidade de repensar os valores importantes à sociedade, bem como uma nova adequação jurídica, visto que se considerado o embrião como um ser humano, há que se ponderar se também será uma pessoa, ou então, uma pessoa em potencial, e se receberá o mesmo tratamento, ou diferenciado, quando o embrião encontra-se em laboratório, e quando está no útero.

Sem dúvida inúmeras possibilidades existem, e nem sempre o Direito encontrará respostas exatas e prontas, pois o Direito se constrói dia-a-dia.

Para citar, os Estados Unidos que são signatários da Convenção Americana de Direito Humanos (Pacto de San José da Costa Rica), mas não do Protocolo de San Salvador, votou no último dia 11 de janeiro de 2007 a suspensão as restrições com pesquisas com células-tronco embrionárias:

A Câmara dos Representantes dos Estados Unidos, agora controlada pela maioria democrata, votou dia 11 de janeiro de 2007 a suspensão das restrições impostas pelo presidente George W. Bush ao financiamento federal de pesquisas com células-tronco embrionárias. E ainda, que em pesquisa de opinião recentes sugerem que os americanos apóiam os estudos com células-tronco embrionárias. ${ }^{75}$

Assim, a dignidade humana norteia as políticas em relação às pesquisas com células-tronco embrionárias.

No dizer de Flávia Piovesan em relação ao sistema interamericano “o sistema interamericano tem revelado, sobretudo, dupla vocação: impedir retrocessos e

75 EUA vota suspensão de financiamento às células-tronco. Disponível em: <http//: www.BBCbrasil.com>. Acesso em 12 jan. 2007. 


\section{PESQUISAS COM CÉLULAS-TRONCO EMBRIONÁRIAS E A CONVENÇÃO AMERICANA DE DIREITOS}

HUMANOS - PACTO DE SAN JOSÉ DA COSTA RICA

fomentar avanços no regime de proteção dos direitos humanos, sob a inspiração de uma ordem centrada no valor da absoluta prevalência da dignidade humana".76

\section{CONSIDERAÇÕES FINAIS}

Diante do exposto, e da argumentação apresentada, constata-se que os avanços da biotecnologia são inevitáveis, e conseqüentemente constroem novas realidades sociais, quais cabem ao direito compor, interpretando as reais necessidades do ser humano. Para isso o direito buscará soluções, com base na garantia de um mínimo protetivo, salvaguardando direitos essenciais, como à vida, à saúde e à dignidade.

O Direito, neste quadro, deve se limitar a regular o que é de interesse comum a todos, observando o que de mais precioso traz o princípio da Igualdade: tratar os desiguais de forma desigual, na medida de suas desigualdades, uma vez justificadas as diferenças.

Sem dúvida os avanços da biotecnologia, principalmente no que dizem respeito às pesquisas com células-tronco embrionárias, os questionamentos são inúmeros e as incertezas maiores ainda, entretanto é preciso definir exatamente o papel do Direito.

O estudo revela que a doutrina se divide em relação ao início da vida, de modo que se torna difícil estabelecer um critério como certo e outro errado, e justamente essa dificuldade de um critério único para o início da vida, traz repercussão em relação à valoração da pessoa humana.

De modo que, a princípio, mesmo adotando a fecundação como início da vida, e conferindo a natureza humana ao embrião, não significa dizer que o embrião possui a mesma condição de pessoa nascida. Ao passo que considerar o embrião uma pessoa,

\footnotetext{
${ }^{76}$ PIOVESAN, op. cit., p. 251.
} 
torna as pesquisas com células-tronco embrionárias inaceitáveis.

Portanto, constata-se um choque de direitos, aliás, um choque entre os possíveis "sujeitos" de direito em relação à vida do embrião, e o direito do enfermo e até mesmo das futuras gerações.

Assim, ao tratar das pesquisas com células-tronco embrionárias, trata-se de condutas de vida, qualidade de vida, em termos individuais e coletivos. A vontade de viver, ou a vontade de abreviar um sofrimento irreversível.

A utilização de células-tronco em terapias, o eventual melhoramento passa obrigatoriamente pelo bem comum existente no Direito, na saúde e na filosofia, ética a dignidade.

O permanente conflito entre a prevalência ou não do valor à, coletivo ou difuso, sobre o direito individual fundamental merece estudo permanente porquanto não existe uma fórmula pronta ou padrão a ser seguido.

Nessa perspectiva, observa-se o tratamento dado à vida no sistema Interamericano de proteção aos direitos humanos, sendo que da análise constata-se que os direitos não são analisados isoladamente, mas em conjunto e com uma interpretação voltada à proteção mínima de direitos, essenciais à vida, como a dignidade da pessoa humana.

Portanto, em linhas gerais, o sistema interamericano com fulcro nos artigos 10, 18 e 22 do Protocolo de San Salvador e 11 do Pacto de San José da Costa Rica viabilizam as pesquisas com células-tronco embrionárias, ao passo que uma leitura isolada do artigo $4^{\circ}$ do Pacto de San José da Costa Rica, inviabiliza, adotando a fecundação como início da vida, considerando que a Convenção traz a proteção desde a concepção, e ainda entende pessoa como todo ser humano.

Sem dúvida o ser humano é dotado de valoração, a qual independe de seu estágio de desenvolvimento, e mesmo que seja considerado em sua potencialidade de desenvolvimento, continua a ter a possibilidade de tornar-se um ser humano, portanto, único, individual, com caracteres próprios e com valoração condizente à sua dignidade 


\section{PESQUISAS COM CÉLULAS-TRONCO EMBRIONÁRIAS E A CONVENÇÃO AMERICANA DE DIREITOS \\ HUMANOS - PACTO DE SAN JOSÉ DA COSTA RICA}

humana.

Entretanto, cabe destacar que este mesmo embrião permanecerá eternamente criopreservado em laboratório, caso não seja levado a termo o projeto parental, neste ínterim pessoas acometidas por enfermidades graves poderão aguardar interminavelmente por uma possível resposta às suas mazelas.

Desta feita, conclui-se que de um modo geral, com amparo de uma interpretação sistemática e evolutiva de proteção à vida voltada à dignidade da pessoa humana, no sentido que a garantia da vida não é suficiente sem dignidade, as pesquisas com células-tronco embrionárias no sistema Interamericano encontra guarida.

Destarte, não se trata de negar direito à vida dos embriões criopreservados em laboratórios, ou, de não lhes reconhecer proteção, trata-se de uma escolha e uma ponderação de valores, as quais deverão resguardar o mínimo de direitos a todos os envolvidos no processo científico, seja ele um embrião, um receptor, pois todos são dotados da qualidade humana, de uma valoração. Contudo, nada pode ser maior que o direito à vida com dignidade.

\section{REFERÊNCIAS}

ALVES, João Evangelista dos Santos. Direitos humanos, sexualidade e integridade na transmissão da vida. In: PENTEADO, Jaques de Camargo e outros. A vida dos direitos humanos - bioética médica e jurídica. Porto Alegre: Fabris, 1999. p. 185-258.

BARBOZA, Heloisa Helena. A filiação em face da inseminação artificial e da fertilização in vitro. Rio de Janeiro: Renovar, 1993.

BARRETTO, Vicente de Paulo. Bioética, biodireito e direitos humanos. Disponível em: <http://www.dhnet.com.br> Acesso em: 1 jul. 2006.

BOBBIO, Norberto. A era dos direitos. Trad. Carlos Nelson Coutinho. Rio de Janeiro: Campus, 1992.

BRANDÃO, Dernival da Silva. O embrião e os direitos humanos. O aborto terapêutico. In: PENTEADO, Jaques de Camargo e outros. A vida dos direitos 
humanos - bioética médica e jurídica. Porto Alegre: Fabris, 1999. p. 15-64.

COMPARATO, Fábio Konder. A afirmação histórica dos direitos humanos. 3. ed. São Paulo: Saraiva, 2003.

DALLARI, Dalmo de Abreu Dallari. Bioética e direitos humanos. Disponível em: $<$ http//:www.dhnet.com.br> Acesso em: 22 jul. 2006.

DINIZ, Maria Helena. O estado atual do biodireito. 2. ed. São Paulo: Saraiva, 2002.

EUA vota suspensão de financiamento às células-tronco. Disponível em: <http//: www.BBCbrasil.com>. Acesso em 12 jan. 2007.

FRANÇA, Genival Veloso de. Aborto: breves reflexões sobre o direito de viver. Disponível em: <http://www.montfort.org.brelanca_celulastronco> Acesso em: 30 jun. 2006.

GOLDIN, José Roberto. O que é o embrião. In: KIPPER, Décio José e outros. Ética em pesquisa: reflexões. Porto Alegre: EDIPUCRS, 2003. p. 55-61.

GOODFIELD, June. Brincando de Deus - a engenharia genética e a manipulação da vida. Belo Horizonte: Itatiaia, 1994.

GRACIANO, Lílian Lúcia. Reprodução humana medicamente assistida e o direito de procriar. In: CASTRO, Rodrigo Pironti Aguirre e outros. A advocacia iniciante e os novos rumos do direito - estudo aplicado. Curitiba: OAB/PR, 2006. t. 2, p. 349-366.

LEITE, Eduardo de Oliveira. Da bioética ao biodireito: reflexões sobre a necessidade e emergência de uma legislação. In: SIMPÓSIO DE BIOÉTICA E BIODIREITO, Londrina, 1999.

2004 .

Grandes temas da atualidade - bioética e biodireito. Rio de Janeiro: Forense,

Procriações artificiais e o direito. São Paulo: RT, 1995.

MACHADO, Maria Helena. Reprodução humana assistida - aspectos éticos \& jurídicos. Curitiba: Juruá, 2003.

MARQUES, Cláudia Lima. A crise científica do direito na pós-modernidade e seus reflexos na pesquisa. Cidadania e Justiça, n. 6, 1999.

MARTINS, Judith Costa; GOLDIN José Roberto. Lei de biossegurança - medusa legislativa? Jornal da ADUFRGS, n. 134, p. 19-21, maio 2005.

MARTINS, Ives Gandra da Silva. O direito do ser humano à vida. In: (coord.). Direito fundamental à vida. São Paulo: Quartier Latin. Centro de Extensão Universitária, 2005. 
PESQUISAS COM CÉLULAS-TRONCO EMBRIONÁRIAS E A CONVENÇÃO AMERICANA DE DIREITOS HUMANOS - PACTO DE SAN JOSÉ DA COSTA RICA

MEIRELLES, Jussara Maria de Leal. A vida humana embrionária e a sua proteção jurídica. Rio de Janeiro: Renovar, 2000.

In: BARBOZA, Heloisa Helena; BARRETO Vicente de Paulo e outros. Temas de biodireito e bioética. Rio de Janeiro: Renovar, 2001. p. 85-97.

MELARÉ, Márcia Regina Machado. Direito à vida: sim às pesquisas com célulastronco embionárias. Revista Consultor Jurídico, 2 mar. 2005. Disponível em: <http://conjur.estadao.com.br/static/text/33284,1> Acesso em: 7 set. 2006.

MELLO, Gustavo Miguez de. Direito fundamental à vida. In: SILVA, Ives Gandra da (coord.). Direito fundamental à vida. São Paulo: Quartier Latin. Centro de Extensão Universitária, 2005. p. 264-283.

MORAES, Mabel Cristiane. A proteção dos direitos humanos e sua interação diante do princípio da dignidade da pessoa humana. Jus Navigandi, Teresina, a. 8, n. 157, 10 dez. 2003. Disponível em: <http://jus2.uol.com.br/doutrina/texto.asp?id=4607>. Acesso em: 22 jul. 2006.

PENTEADO, Jaques de Camargo e outros. A vida dos direitos humanos - bioética médica e jurídica. Porto Alegre: Fabris, 1999.

PIOVESAN, Flávia. Direitos humanos e o direito constitucional internacional. São Paulo: Saraiva, 2006.

SANTOS, Maria Celeste Cordeiro Leite dos Santos. Imaculada Concepção: nascendo in vitro e morrendo in machina. São Paulo: Acadêmica, 1993.

SAUWEN, Regina; HRYNIEWICZ, Severo. O direito "in vitro": da bioética ao biodireito. Rio de Janeiro; Lumen Juris, 1997.

SCARPARO, Mônica Sartori. Fertilização assistida; questão aberta: aspectos científicos e legais. Rio de Janeiro: Forense Universitária, 1991.

SIQUEIRA, Marília. O início da vida e a medicina atual. In: PENTEADO, Jaques de Camargo e outros. A vida dos direitos humanos - bioética médica e jurídica. Porto Alegre: Fabris, 1999. p. 335-352.

TRINDADE, Antônio Augusto Cançado. A proteção internacional dos direitos humanos e o Brasil (1948-1997): as primeiras cinco décadas. 2. ed. Brasília: UnB, 2000 .

TRINDADE, Antônio Carlos. Tratado internacional dos direitos humanos. Porto Alegre: Fabris, 1997. v. 1.

ZATZ, Mayana. Entrevista à Folha Online em 13.03.04. Coordenadora do Centro de Estudos do Genoma Humano da USP. In: MEDEIROS, Leonardo. Cientista da USP defende pesquisas com células-tronco embrionárias. Disponível em: 
Revista Eletrônica do CEJUR, Curitiba-PR, a. 2, v. 1, n. 2, ago./dez. 2007

<http://www1.folha.uol.com.br/folha/ciencia/ult306u11310.shtml>. Acesso em: 7 jan. 2007. 